\title{
AEROSOL OPTICAL PROPERTIES VARIABILITY DURING BIOMASS BURNING EVENTS OBSERVED BY THE EOLE-AIAS DEPOLARIZATION LIDARS OVER ATHENS, GREECE (2007-2016)
}

\author{
Maria Mylonaki ${ }^{1}$, Alexandros Papayannis ${ }^{1 *}$, Rodanthi Mamouri ${ }^{2}$, Athina Argyrouli ${ }^{1}$, Panagiotis \\ Kokkalis $^{1}$, Georgios Tsaknakis ${ }^{1}$ and Ourania Soupiona ${ }^{1}$ \\ ${ }^{1}$ National Technical University of Athens, Laser Remote Sensing Unit, Physics Department, Zografou, \\ Greece,*apdlidar@central.ntua.gr \\ ${ }^{2}$ Cyprus University of Technology, Dep. of Civil Engineering and Geomatics, Limassol, Cyprus
}

\begin{abstract}
The EOLE multi-wavelength aerosol Ramandepolarization lidar, and the AIAS depolarization lidar, in synergy with a sun photometer (CIMEL), were used, in the period 2007-2016, to provide the vertical profiles of the aerosol optical properties over Athens, Greece. More than 30 biomass burning events (fresh and aged smoke particles) were observed, with smoke layers between 1.5 up to $4-5 \mathrm{~km}$ height, while their duration ranged from 1-3 days. Lidar ratio (LR) values ranged from 40-105 sr (at $355 \mathrm{~nm}$ ) and from 40-100 sr (at 532 $\mathrm{nm}$ ), while the linear particle depolarization ratio (LPDR) at both 355 and $532 \mathrm{~nm}$, remained $<7 \%$. The extinction-related Ångström exponent $\left(\mathrm{AE}_{\mathrm{a}}\right)$ at 355 $\mathrm{nm} / 532 \mathrm{~nm}$ ) ranged from 0.3 to 2.1 . Additionally, a case of a near-range transport of biomass burning aerosols arriving over Athens up to $4 \mathrm{~km}$ height, between 27 and 28 June 2016, was studied. For this case, we found LRs of the order of $70 \pm 5 \mathrm{sr}(355 \mathrm{~nm})$ and $65 \pm 15 \mathrm{sr}(532 \mathrm{~nm})$ and $\mathrm{AE}_{\mathrm{a}}(355 \mathrm{~nm} / 532 \mathrm{~nm})$ around 1 .
\end{abstract}

\section{INTRODUCTION}

Wildfires play a substantial role in terrestrial ecosystems and have severe atmospheric and climatic effects (e.g. emission/production of global warming gases/aerosols: $\mathrm{CO}_{2}, \mathrm{O}_{3}$, aerosol particles, etc.) due to the emission of huge quantities of gases. Recent estimations of the global annual burned areas are of the order of more than 350 Mha per year [1-2], while the annual emissions of $\mathrm{CO}_{2}$ are estimated to be of the order of 2.1 Pg C per year [1]. For the period 19792013 large wildfires caused a doubling of global burnable area strongly affected by the prolonged fire weather seasons in conjunction with an increased frequency of long fire weather seasons after 1996 [2].

In Europe, during the summer and early autumn period's large wildfires and agricultural biomass burning (BB) events, for several days, occur quite frequently, mainly in Southern Russia, Ukraine,
Southern Europe and the Balkans, thus affecting large areas of Eastern-South-Eastern Europe through longrange transport of air masses [2-6].

Moreover, during the recent years (2010-today) of economic recession, in many European countries (Greece, Poland, UK, Spain, Ukraine, etc.), during the winter period, people have switched their domestic heating from oil to uncontrolled wood and biomass combustion [7]. This has caused a detrimental air quality deterioration by augmenting the ambient particulate matter (PM), exceeding by far the EU daily limit values, especially in Athens, Greece [8]. For instance, actually Athens is considered as the $4^{\text {th }}$ most air polluted city in the European Union due to wood burning activities during winter time [7].

Wildfire and wood burning atmospheric emissions contain/produce greenhouse gases like $\mathrm{CO}_{2}, \mathrm{CH}_{4}, \mathrm{NOx}$, NMHCs, $\mathrm{N}_{2} \mathrm{O}, \mathrm{O}_{3}$, and other toxic ones, like $\mathrm{CO}$, VOCs, $\mathrm{Hg}$, PAHs, as well as biomass burning aerosols, which strongly affect air quality up to several thousands of kilometers [3]. As these aerosols play a substantial role in Earth's climate (e.g. direct and indirect effect) [3] and human health, it becomes very important to measure their optical, microphysical and chemical properties in a global scale on a long-term basis.

Although intensive campaigns have been performed worldwide to measure and characterize the biomass burning aerosols, long-term measurements are still missing, especially in areas like the Mediterranean region, which is largely affected by long-range transport of $\mathrm{BB}$ particles from Southern Russia and Ukraine [5], and by numerous forest fires and biomass burning events occur on an annual basis [6, 8-10].

Raman lidars have proven to be an appropriate tool in aerosol characterization of biomass burning aerosols, since they can provide the vertical profiles of the aerosol optical ( $\left.\beta_{\mathrm{aer}}, \alpha_{\mathrm{aer}}, \mathrm{LR}, \mathrm{LPDR}\right)$ and microphysical properties with high spatial and temporal resolution during many $\mathrm{BB}$ events observed mainly over Europe [10-16]. Besides, their chemical properties can be 
estimated aloft, using thermodynamic models and relative humidity observations [17].

\section{METHODOLOGY}

A synergy of instruments (Raman and elastic depolarization lidars and sun photometer) and tools (HYSPLIT model and satellite data from MODIS sensor) were used to derive the aerosol optical properties aloft, during biomass burning events observed over Athens, for a 10-year period (20072016). The Athens Raman depolarization lidar system (EOLE) was run in parallel with the AIAS depolarization lidar, in the frame of ARIADNE, the Greek lidar network [18]. Both systems are based in the Laser Remote Sensing Unit (LRSU) of the National Technical University of Athens (NTUA) $\left(37.9^{\circ} \mathrm{N}\right.$, 23. $6^{\circ} \mathrm{E}, 200 \mathrm{~m}$ a.s.1.).

EOLE (Fig. 1-left) is able to perform independent and simultaneous measurements of the vertical profiles of extensive aerosol parameters, $\beta_{\text {aer }}$ (at 355, 532 and 1064 $\mathrm{nm}$ ), $\alpha_{\text {aer }}$ (at 355 and $532 \mathrm{~nm}$ ), as well as of the water vapor mixing ratio in the troposphere (using the $\mathrm{H}_{2} \mathrm{O}$ Raman channel at $407 \mathrm{~nm}$ ). AIAS (Fig. 1-right) provides the aerosol backscatter coefficient and the linear particle depolarization ratio at $532 \mathrm{~nm}$. The AERONET CIMEL sun photometer (Fig. 1-middle) is operating at the National Observatory of Athens (NOA) (www.aeronet.gsfc.nasa.gov).
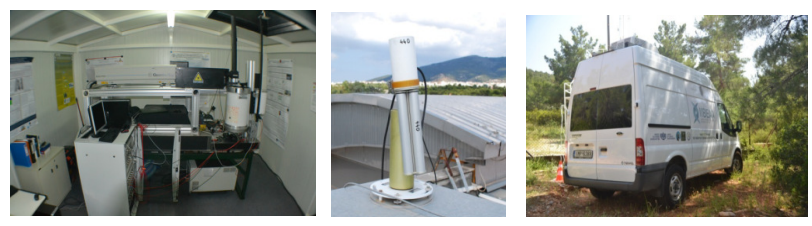

Figure 1. EOLE lidar system (left), NOA CIMEL sun photometer (middle), AIAS mobile aerosol depolarization lidar system (right).

In addition, HYSPLIT model and MODIS sensor data were used for the characterization of the air masses arriving over our site.

Moreover, the EOLE multi-wavelength Raman lidar data were used to derive the vertical profiles of the aerosol intensive properties: LR (at 355 and $532 \mathrm{~nm}$ ), $\mathrm{AE}_{\mathrm{a}}$ and backscatter-related Ångström exponent $\left(\mathrm{AE}_{\mathrm{b}}\right)$ of the aerosols at 355-532-1064 nm, and LPDR at 355 $\mathrm{nm}$. Due to the weak Raman signals, the complete set of aerosol products can be derived for tropospheric layers only during nighttime. The data processing was based on the Single Calculus Chain (SCC) developed within EARLINET [19] and on manual retrievals. Sun photometry data were provided by the AERONET CIMEL sun photometer.
For this study, based on the combined data from the EOLE and AIAS lidars, we compared our results (LR and LPDR at 355 and $532 \mathrm{~nm}$, AEa at $355 \mathrm{~nm} / 532 \mathrm{~nm}$ ), with those reported in the literature [12-16].

\section{RESULTS}

In the period under study we sampled more than 30 clear biomass burning events, with fresh and aged smoke particles over Athens, Greece with smoke layers between 1.5 up to $4-5 \mathrm{~km}$ height, and duration of 1-3 days. Fig. 2 shows LR versus LDR (left), LR versus $\mathrm{AE}_{\mathrm{a}}$ (middle), as well as LPDR versus $\mathrm{AE}_{\mathrm{a}}$ (right), all at $532 \mathrm{~nm}$, except for $\mathrm{AE}_{\mathrm{a}}(355 \mathrm{~nm} / 532 \mathrm{~nm})$, for fresh $(\leq 3$ days) and aged (> 3 days) BB aerosols. The data are taken from [10-16] (denoted with squares) and from our measurements (denoted with stars). We can see that our data are, mostly, in good accordance with literature data obtained in Europe.
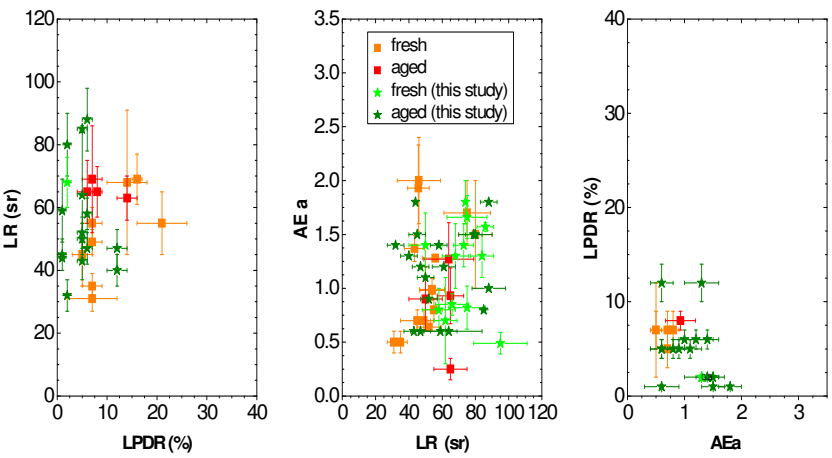

Figure 2. LR (532 nm) versus LPDR (532 nm) (left), LR (532 $\mathrm{nm})$ versus $\mathrm{AE}_{\mathrm{a}}$ (middle), $\mathrm{LPDR}(532 \mathrm{~nm})$ versus $\mathrm{AE}_{\mathrm{a}}$ (right) $(355 \mathrm{~nm} / 532 \mathrm{~nm})$ for fresh and aged BB particles [literature data (squares) and current study data (stars)].
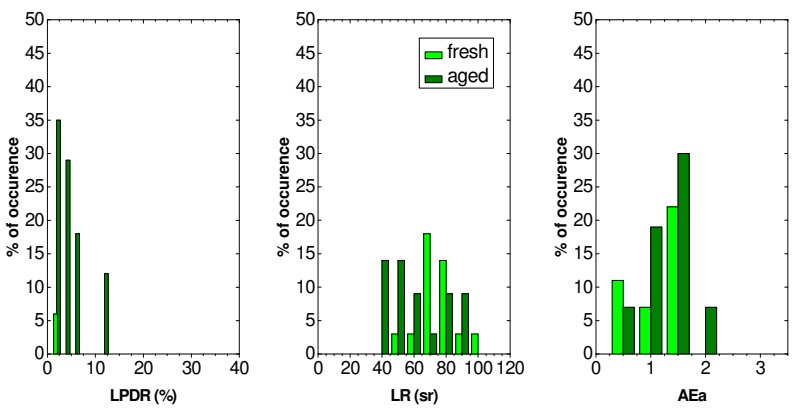

Figure 3. Frequency of occurrence (\%) of LPDR (532 $\mathrm{nm}), \operatorname{LR}(532 \mathrm{~nm})$ and $\mathrm{AE}_{\mathrm{a}}(355 \mathrm{~nm} / 532 \mathrm{~nm})$ for fresh and aged BB particles (our study). 


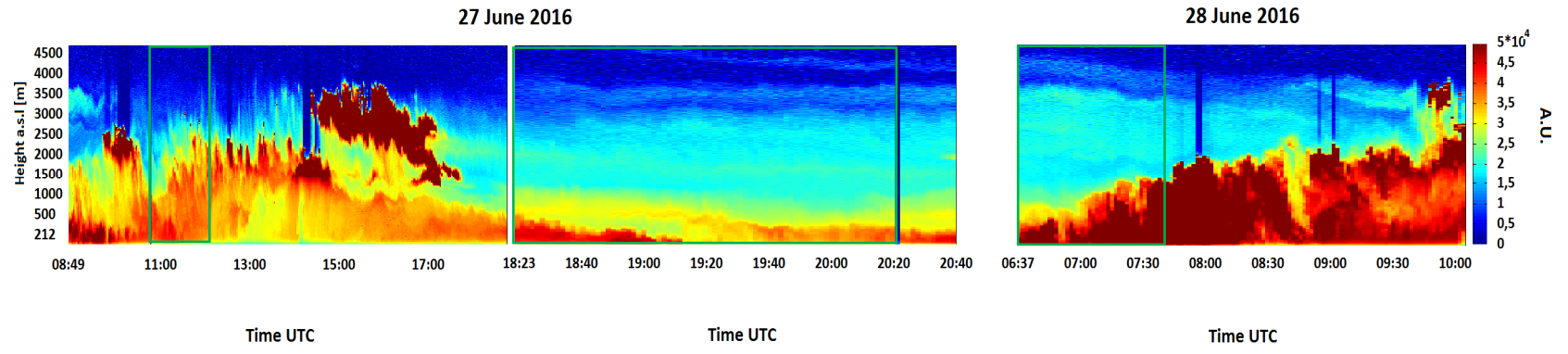

Figure 4. Spatio-temporal evolution of the range-corrected (RCS) backscattered lidar signals at $1064 \mathrm{~nm}$ obtained by EOLE over Athens for 27 June (day and night) and 28 June (day) 2016.
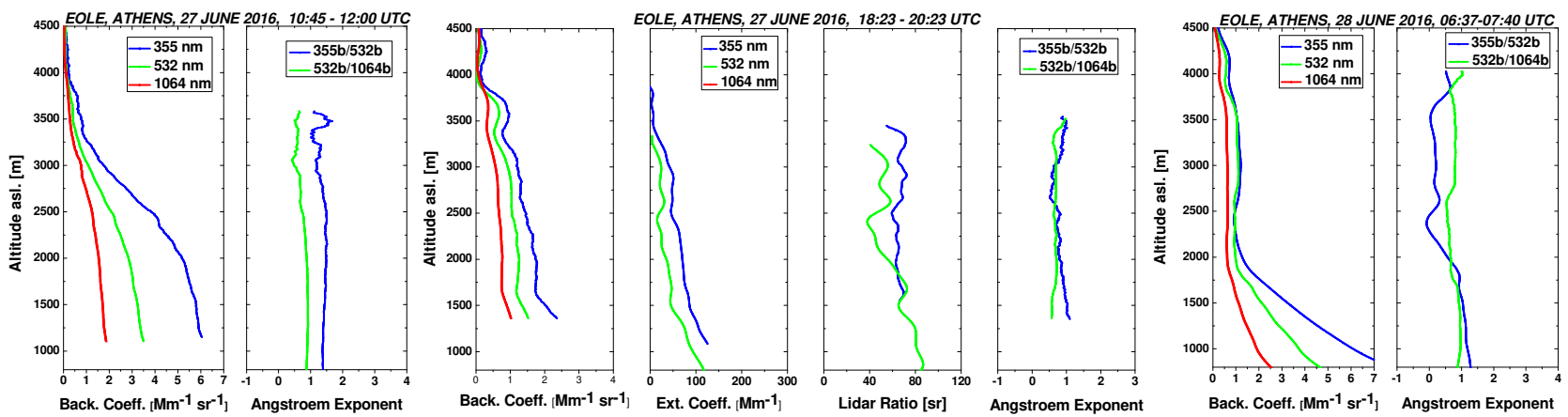

Figure 5. Vertical profiles of $\beta_{\text {aer }}, \alpha_{\text {aer }}, \mathrm{LR}, \mathrm{AE}_{\mathrm{b}}$ at 355, 532, $1064 \mathrm{~nm}$, obtained by the EOLE system on 27 June (day and night) and 28 June (day) 2016.

In Fig. 3 we present the frequency of occurrence (\%) of LPDR, LR and $\mathrm{AE}_{\mathrm{a}}(355 \mathrm{~nm} / 532 \mathrm{~nm})$ for fresh and aged BB particles at $532 \mathrm{~nm}$, as measured over our station. We see that in more than $80 \%$ of the cases we studied, LPDR $<7 \%$ (aged), $40 \mathrm{sr}<\mathrm{LR}<105 \mathrm{sr}$ (fresh and aged), while $1.2<\mathrm{AEa}<1.6$ (aged) and $0.4<\mathrm{AEa}<1.4$ (fresh). Based on observations we found that $\operatorname{LR}(355 \mathrm{~nm})=$

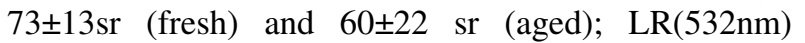
$=71 \pm 15 \mathrm{sr}$ (fresh) and $60 \pm 18 \mathrm{sr}$ (aged). These values are in good agreement with relevant published ones [1016].

\section{CASE STUDY}

A case study of fresh BB particles from a wildfire occurred about $20 \mathrm{~km}$ from NTUA, in Parnis (Attika) mountain, between 27-28 June 2016 will be analyzed, regarding the aerosol optical properties: $\beta_{\text {aer }}(355,532$, $1064 \mathrm{~nm}), \alpha_{\text {aer }}(355,532 \mathrm{~nm}), \operatorname{LR}(355,532 \mathrm{~nm})$, $\mathrm{AE}_{\mathrm{a}}(355 \mathrm{~nm} / 532 \mathrm{~nm})$ and $\mathrm{AE}_{\mathrm{b}}(355 \mathrm{~nm} / 532 \mathrm{~nm})$ and $\mathrm{AE}_{\mathrm{b}}(532 \mathrm{~nm} / 1064 \mathrm{~nm})$.

In Fig. 4 we present the spatio-temporal evolution of the range-corrected (RCS) lidar signal at $1064 \mathrm{~nm}$ obtained by EOLE for 27 June (08:49-20:40 UTC, day and night) and 28 June (06:37-10.00 UTC, day) 2016. Smoke layers are seen between 2.5 and $4.5 \mathrm{~km}$ height (in light blue-green color) over the locally produced particles within the PBL (from ground up to $2-2.5 \mathrm{~km}$ height, in yellow-red color). Scattered clouds are formed at the top of the PBL or above it at 1.5-3.5 km height (i.e., between 14:30-17:00 UTC), on 27 June 2016.

In Fig. 5 we show the vertical profiles of $\beta_{\text {aer }}, \alpha_{\text {aer }}, L R$, $\mathrm{AE}_{\mathrm{b}}$ obtained by the EOLE system at $355,532,1064$ $\mathrm{nm}$, on 27 (10:45-12:00 UTC \& 18:23-20:23 UTC) and 28 June (06:37-07:40 UTC) 2016. We found LRs of the order of $70 \pm 5 \mathrm{sr}(355 \mathrm{~nm})$ and $65 \pm 15 \mathrm{sr}(532 \mathrm{~nm})$ and $\mathrm{AE}_{\mathrm{a}}(355 \mathrm{~nm} / 532 \mathrm{~nm})$ around 1 .

\section{CONCLUSIONS}

Multi-wavelength aerosol Raman lidar and sun photometer data were used, over a 10-year period (2007-2016), to provide the vertical profiles of the aerosol optical properties over Athens, Greece. We studied more than 30 intense biomass burning events originating from forest and agricultural fires mainly over Europe (Russian Federation, Ukraine, Romania, Italy, Greece, etc.). These events comprised fresh and aged smoke particles, with layers between 1.5 up to 4-5 $\mathrm{km}$ height and of duration of $\sim 1-3$ days. The statistical analysis of the aerosol optical properties derived by EOLE and AIAS [LR(355-532 nm, LPDR(532 nm), $\left.\mathrm{AE}_{\mathrm{a}}(355 \mathrm{~nm} / 532 \mathrm{~nm})\right]$ showed that: $40 \mathrm{sr}<\mathrm{LR}<105 \mathrm{sr}$ $(355 \mathrm{~nm})$ and $40 \mathrm{sr}<\mathrm{LR}<100 \mathrm{sr}(532 \mathrm{~nm}), \mathrm{LPDR}<7 \%$, in most cases and $0.3<\mathrm{AE}_{\mathrm{a}}(355 \mathrm{~nm} / 532 \mathrm{~nm})<2.1$. Our observations, when compared with those reported in the literature concerning various biomass burning events (fresh and aged) observed by Raman lidars, showed good agreement. A case study (27-28 June 2016) of near-range transport of biomass burning aerosols over 
Athens showed smoke layers up to 4-4.5 $\mathrm{km}$ a.s.l., with $\mathrm{LR} \approx 70 \pm 5 \mathrm{sr}(355 \mathrm{~nm}), \mathrm{LR} \approx 65 \pm 15 \mathrm{sr}(532 \mathrm{~nm})$ and $\mathrm{AE}_{\mathrm{a}}$ $(355 \mathrm{~nm} / 532 \mathrm{~nm}) \approx 1$.

\section{ACKNOWLEDGMENTS}

The research leading to these results has received funding from the European Union $6^{\text {th }} \& 7^{\text {th }}$ Framework Programmes (FP6 and FP7 under grant agreement RICA-025991 and no 262254, as well as from Horizon 2020 ACTRIS research/innovation programme under grant agreement $n^{\circ} 654109$. The work of AP and AA has received funding from the European Union Seventh Framework Programme (FP7/2007-2013): People, ITN Marie Curie Actions Programme (2012-2016) in the frame of ITaRS, under grant agreement $\mathrm{n}^{\circ} 289923$. The authors gratefully acknowledge the NOAA Air Resources Laboratory for the provision of the HYSPLIT transport and dispersion model and READY website (http://www.ready.noaa.gov) used in this publication. MODIS-FIRMS data were provided by EARTHDATA (EOSDIS-NASA). The AERONET sun photometer data were provided by the National Observatory of Athens [PI Dr. V. Amiridis]. The Biomedical Research Foundation of the Academy of Athens is acknowledged for the provision of the lidar mobile platform.

\section{References}

[1] Chuvieco, E., et al., 2016: A new global burned area product for climate assessment of fire impacts, Global Ecology and Biogeography, 25, pp. 619-629.

[2] Jolly, W. M., et al., 2015: Climate-induced variations in global wildfire danger from 1979-2013, Nature Communications, 6:7537, doi: 10.1038/ncomms8537.

[3] IPCC, 2014: Intergovernmental Panel on Climate Change: Climate Change 2013: Synthesis Report.

[4] Wotawa, G., 2001: Interannual variability of summertime $\mathrm{CO}$ concentrations in the Northern Hemisphere explained by boreal forest fires in North America and Russia, Geophys. Res. Lett., 28, 45754578 .

[5] Amiridis, V., et al., 2009: Optical characteristics of biomass burning aerosols over Southeastern Europe determined from UV-Raman lidar measurements, Atmos. Chem. Phys., 9, 2431-2440.

[6] Bougiatioti, A., et al., 2014: Processing of biomassburning aerosol in the eastern Mediterranean during summertime, Atmos. Chem. Phys., 14, 4793-4807.

[7] European Environment Agency (EEA), Air Quality in Europe, 2016 Report, EEA Report No 28/2016, 2016.
[8] Paraskevopoulou, D. et al., 2016: Long term characterization of organic and elemental carbon in the $\mathrm{PM}_{2.5}$ fraction: the case of Athens, Greece, Atmos. Chem. Phys. 14, 13313-13325.

[9] Bougiatioti, A., et al., 2016: Biomass-burning impact on CCN number, hygroscopicity and cloud formation during summertime in the eastern Mediterranean, Atmos. Chem. Phys., 16, 7389-7409.

[10] Nicolae, D., et al., 2013: Characterization of fresh and aged biomass burning events using multiwavelength Raman lidar and mass spectrometry, $J$. Geophys. Res., 118, 2956-2965.

[11] Wandinger, U., et al., 2002: Optical and microphysical characterization of biomass burning and industrial-pollution aerosols from multi-wavelength lidar and aircraft measurements, J. Geophys. Res., 107, D21, 8125 .

[12] Balis, d., et al., 2003: Raman lidar and sun photometric measurements of aerosol optical properties over Thessaloniki, Greece, during a biomass burning episode, Atmos. Environ., 37, 4529-4538.

[13] Müller, D., et al., 2005: Raman lidar observations of aged Siberian and Canadian forest fire smoke in the free troposphere over Germany, in 2003: microphysical particle characterization, J. Geophys. Res., 110, D17201.

[14] Gross, S., et al., 2013: Aerosol classification by airborne high spectral resolution lidar observations, Atmos. Chem. Phys., 13, 2487-2505.

[15] Giannakaki, E., et al., 2016: Optical and microphysical characterization of aerosol layers over S. Africa by means of multi-wavelength depolarization and Raman lidar measurements, Atmos. Chem. Phys., 16, 8109-8123.

[16] Müller, D., et al., 2007: Aerosol-type-dependent lidar ratios observed with Raman lidar, J. Geophys. Res., 112, D16202.

[17] Mamouri et al., 2012: Multi-wavelength Raman lidar, sun photometric and aircraft measurements in combination with inversion models for the estimation of the aerosol optical and physico-chemical properties over Athens, Greece, Atmos. Meas. Tech., 5, 17931808.

[18] Papayannis, A., et al., 2012: ARIADNE: The Greek Lidar Network, Proc. $26^{\text {th }}$ International Laser Radar Conference, Porto Heli, Greece, 349-352.

[19] d'Amico, G., et al., 2012: EARLINET Single Calculus Chain for automatic lidar data processing: First tests on optical products, Proc. $26^{\text {th }}$ International Laser Radar Conference, Porto Heli, Greece, 331-334. 